\title{
Relationship between serum ferritin and total body iron stores in idiopathic haemochromatosis
}

\author{
L. W. POWEll, J. W. HALliday, AND J. L. COWLiShaW \\ From the Department of Medicine (Section of Hepatology), University of Queensland, Royal Brisbane \\ Hospital, Brisbane, Australia
}

SUMMARY The relationship between the serum ferritin concentration and total body iron stores was investigated in 41 patients with idiopathic haemochromatosis and 199 first or second degree relatives. Thirty-two relatives $(16.1 \%)$ had increased iron stores and serum ferritin levels were increased in all but one of them. The false-positive rate in the relatives with normal iron stores was $1.8 \%$ compared with $10 \%$ for the serum iron concentration and $33 \%$ for the transferrin saturation. There was a significant correlation between the serum ferritin concentration and both the chelatable body iron and the hepatic iron concentration. We conclude that in the natural history of classical idiopathic haemochromatosis the serum ferritin concentration is usually raised when hepatic iron stores are increased and before there is architectural damage to the liver.

Despite much controversy in the past (Crosby, $1966)$ it is now generally accepted that the disease known as idiopathic haemochromatosis is a clinical entity which results from at least one genetically determined disorder of iron metabolism (Grace and Powell, 1974) and recent evidence suggests that the responsible gene is located on chromosome 6 near the A locus (Simon et al., 1976; 1977). The primary metabolic abnormality is unknown but defects in the handling of iron by both the intestinal mucosal cell (Powell et al., 1970; Cox and Peters, 1978) and the reticuloendothelial cell (Fillet and Marsaglia, 1975) have been demonstrated. The disease is characterised by inappropriately high absorption of dietary iron with progressive deposition of iron in the parenchymal cells of the liver and other organs with eventual fibrosis and organ failure (Grace and Powell, 1974). Phlebotomy therapy has been widely used for over 20 years and during that time substantial evidence has accumulated that rigorous venesection therapy prolongs life and may prevent or delay irreversible complications such as cirrhosis, malignant hepatoma, and gonadal atrophy (Williams et al., 1969; Powell, 1970; Bomford et al., 1976). Moreover, hepatic cirrhosis appears to be an important prerequisite for the development of primary liver cell cancer and

Address for correspondence: Professor L. W. Powell, Department of Medicine, University of Queensland, Royal Brisbane Hospital, Brisbane 4029, Australia. even complete removal of iron after the development of cirrhosis does not necessarily prevent the development of this tumour (Powell and Kerr, 1975; Bomford et al., 1976). Thus, there has been increasing emphasis in recent years on the early detection of iron overload in the relatives of patients with this disease and much interest now centres on the role of simple non-invasive tests in detecting an early increase in iron stores before tissue damage has occurred.

The unreliability of the plasma iron and the transferrin saturation in detecting increased iron stores (Bothwell and Finch, 1962; Crosby et al., 1974) has resulted in reliance on semiquantitative tests using iron chelating agents such as desferrioxamine and also on liver biopsy and the quantitative measurement of liver iron content (Barry et al., 1969; Powell, 1965). However, the former is cumbersome and subject to considerable technical variability and liver biopsy is not without risk. Thus, considerable interest has centred on reports that the serum ferritin concentration correlated well with body iron stores in normal subjects and in patients with iron deficiency or uncomplicated iron storage disease (Jacobs et al., 1972; Lipschitz et al., 1974; Walters et al., 1973). However, early reports of family studies of idiopathic haemochromatosis suggested that the serum ferritin concentration was not a reliable index of iron overload in this disease and that a rise in serum ferritin levels occurred only when liver damage was present 
(Prieto et al., 1975; Wands et al., 1976; Feller et al., 1977). The total number of family studies reported, however, was small.

We have therefore investigated 240 members of 43 families with classical idiopathic haemochromatosis in order to determine the extent to which the above reports were representative. Our previous publication analysed the role of the serum ferritin concentration as a screening test to detect preclinical iron overload in relatives (Halliday et al., 1977). The present paper will focus on the relationship between the serum ferritin concentration and the total body iron stores in these relatives and our conclusions concerning the natural history of idiopathic haemochromatosis.

\section{Methods}

\section{PATIENTS}

Forty-three families with idiopathic haemochromatosis were studied including 41 probands and 199 first or second degree relatives. They constituted part of a prospective study of patients diagnosed in or referred to this unit between January 1974 and June 1977. The probands all displayed classical clinical and pathological features of idiopathic haemochromatosis (Powell, 1970). All available relatives over 10 years of age were investigated. This included a medical history, a physical examination, and the following laboratory investigations; red cell indices, serum iron concentration, total iron binding capacity (TIBC), serum ferritin concentration, serum aspartate transaminase concentration, and measurement of chelatable body iron. Liver biopsy and hepatic iron concentration were performed only if one or more of the above tests was abnormal. The ages of the subjects ranged from 10 to 82 years. All patients with idiopathic haemochromatosis included in this report were first studied before the commencement of phlebotomy therapy.

Serum iron and TIBC were measured by an adaptation of the method of Peters et al. (1956); chelatable iron was estimated by measurement of the 24 hour urinary iron excretion after an intramuscular injection of $0.5 \mathrm{~g}$ desferrioxamine. The urinary iron was measured after acidification by the same method as the serum iron. Liver iron concentration was measured on tissue dried to constant weight which was ashed, dissolved in concentrated hydrochloric acid, and neutralised with sodium hydroxide. Iron concentration was then measured as above.

The serum ferritin concentration was measured by a solid phase radio-immunoassay (Halliday et al., 1975). All samples were measured in duplicate and estimations repeated on a further serum sample if raised. The normal ranges in this laboratory are 20 to $200 \mathrm{ng} / \mathrm{ml}$ for males and 10 to $150 \mathrm{ng} / \mathrm{ml}$ for females. Red cell indices and aspartate transaminase concentration were measured using standard laboratory techniques in the Department of Pathology, Royal Brisbane Hospital. Liver biopsies, after removal of a portion for measurement of iron concentration, processed for routine light microscopy, were stained with haematoxylin and eosin, a reticulin stain, and Perls' Prussian Blue for iron. The histological sections were assessed by one of us and a pathologist without knowledge of the clinical details. The amount of stainable iron in hepatocytes was graded 1 to 4 after Scheuer et al. (1962). According to this grading, grade 1 was regarded as normal and grades 2 to 4 as abnormal (Powell, 1966). Additional assessment of increased iron stores was made retrospectively by repeated phlebotomy whenever possible.

\section{Results}

Individual values have been tabulated previously (Halliday et al., 1977). As stated above the present study will review particularly the relationship between the serum ferritin concentration and the total body iron stores in those subjects with preclinical or latent iron overload and our conclusions concerning the natural history of idiopathic haemochromatosis. A summary of the reliability of the serum iron transferrin saturation and serum ferritin concentration in detecting increased iron stores is given in the Table.

Table Reliability of serum iron concentration, transferrin saturation, and serum ferritin concentration in detecting increased total body iron stores*

\begin{tabular}{lll}
\hline & $\begin{array}{l}\text { False positive } \\
\text { rate }(\%)\end{array}$ & $\begin{array}{l}\text { False negative } \\
\text { rate }(\%)\end{array}$ \\
\hline Serum iron concentration & 10 & 24 \\
Percentage transferrin saturation & 33 & 0 \\
Serum ferritin concentration & 1.8 & 3 \\
\hline
\end{tabular}

*Iron stores were assessed by measurement of chelatable iron, hepatic iron concentration and by repeated phlebotomy (Halliday et al., 1977).

\section{SERUM FERRITIN CONCENTRATION AND} BODY IRON STORES

In this study, the serum ferritin concentration was grossly raised in all 41 probands (range 670 to $4100 \mu \mathrm{g} / \mathrm{l})$. Of the 199 relatives investigated, 32 $(16.1 \%)$ were shown to have increased iron stores by one of the above methods (other than the serum ferritin concentration). The serum ferritin was above 
the upper limit of the normal range with one exception in all relatives in whom increased iron stores were later confirmed. This subject, a 38 year old housewife, is believed to represent the syndrome described by Wands and colleagues (1976) in which the normal serum ferritin level remains unexplained (Halliday et al., 1977). In all other respects the patient's disease resembles classical idiopathic haemochromatosis.

The correlations between the serum ferritin concentration and other indices of iron storage were in agreement with those published by Prieto et al. (1975) and more recently by Edwards et al. (1977). The correlation coefficient for the serum ferritin versus the chelatable iron $(r=0.88)$ was higher than that between the serum ferritin and hepatic iron concentration $(r=0.65)$. Both were significant at the $1 \%$ level.

The Figure illustrates our hypothesis concerning the natural history of idiopathic haemochromatosis and the relation of the serum ferritin concentration to the various stages of the disease.

\section{Discussion}

Although the serum ferritin concentration correlates closely with body iron stores in normal subjects and in patients with iron deficiency, transfusional haemosiderosis or advanced haemochromatosis (Jacobs et al., 1972; Lipschitz et al., 1974; Walters et al., 1973), its value in the diagnosis of early idiopathic haemochromatosis has been questioned. Wands et al. (1976) and Feller et al. (1977) described three families in whom several affected relatives with precirrhotic haemochromatosis had increased body iron stores of up to $15 \mathrm{~g}$ with normal levels for serum ferritin. Wands and his colleagues postulated that the serum ferritin concentration is raised in the later stages of iron accumulation only, after considerable parenchymal cell iron deposition and reticuloendothelial iron accumulation, and they concluded that serum ferritin levels were no more predictive of tissue iron concentrations than measurements of the serum iron, transferrin saturation, or chelatable iron. In the present study of 43 families, the serum iron and transferrin saturation were not reliable indices of increased iron stores (Table). In contrast, serum ferritin levels were raised in all subjects with increased iron stores except one $(98 \%)$. In only three patients $(1.8 \%)$ was the serum ferritin raised in the absence of increased iron stores and all three consumed alcohol to excess. The raised serum ferritin levels in these subjects were presumably caused by hepato-

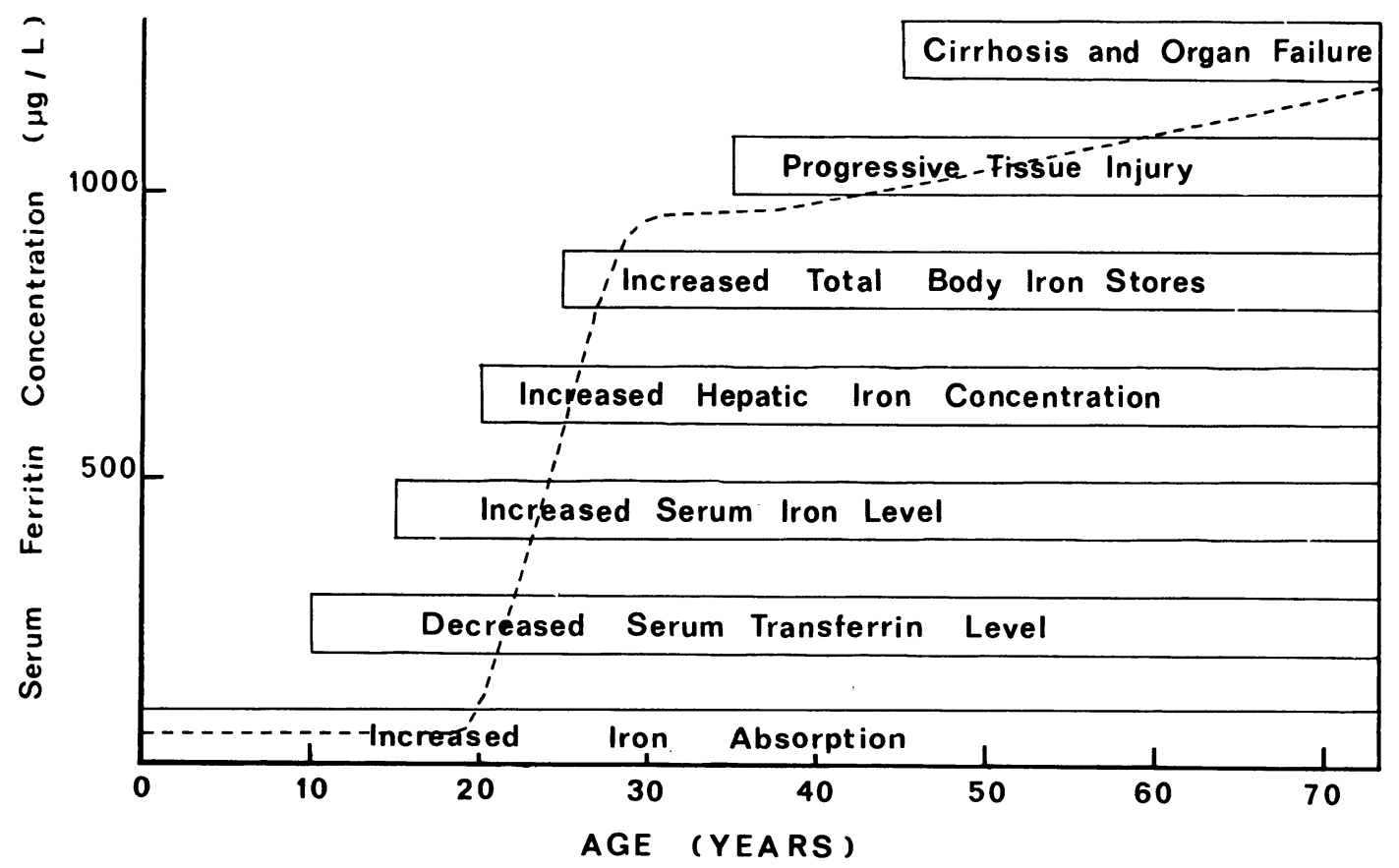

Figure Hypothesis of natural history of idiopathic haemochromatosis and the relationship of the serum ferritin concentration to different stages of the disease (see text). 
cellular damage by alcohol (Prieto et al., 1975) and it is noteworthy that in all three subjects the serum ferritin levels fluctuated widely.

The reason for the normal serum ferritin concentration in the three families reported by Wands and his colleagues and in our one patient remains to be determined. It presumably represents a variant of the disease, perhaps with serum ferritin having different immunological properties. However, for practical purposes it would appear to be a rare disorder, at least in Australia.

On the basis of our observations and the previous literature we propose the hypothesis concerning the natural history of classical idiopathic haemochromatosis that is illustrated in the Figure. An inappropriate increase in iron absorption would appear to be present from birth (Finch and Finch, 1955). An increased serum iron concentration and decreased transferrin level are often seen in younger relatives without an increase in total body iron stores (Williams et al., 1962; Powell, 1965). The next demonstrable abnormality is probably an increase in hepatic iron concentration (Finch and Finch, 1955; Grace and Powell, 1974) and at that stage the serum ferritin level appears to rise (Edwards et al., 1977; Halliday et al., 1977). However, the serum ferritin concentration is not consistently raised until the total body iron stores are increased (Prieto et al., 1975; Edwards et al., 1977; Halliday et al., 1977). In our experience, with the exception of the single case discussed above, the serum ferritin concentration is raised before hepatic fibrosis and cirrhosis develop-a point of considerable practical importance. Once progressive tissue injury and cirrhosis supervene, the level of serum ferritin may rise further because of cell necrosis.

All would probably agree that the most sensitive and reliable index of increased tissue iron stores is the quantitative measurement of liver iron concentration (Bothwell et al., 1962; Finch and Finch, 1955). However, not all would agree that the systematic evaluation of first degree relatives of patients with idiopathic haemochromatosis should necessarily include precutaneous liver biopsy. The results of the present study would suggest that the serum ferritin concentration is a reliable noninvasive screening test for iron overload and that the combination of serum ferritin and serum iron concentrations will allow detection of idiopathic haemochromatosis in the precirrhotic stage. If either test is abnormal liver biopsy and estimation of hepatic iron concentration are indicated. If both tests are repeatedly normal the probability that the subject has increased body iron stores would appear to be very low indeed.
This study was supported by the National Health and Medical Research Council of Australia. We wish to thank Professor J. F. Kerr for assessing the liver-biopsy specimens, the Pathology Department of the Royal Brisbane Hospital for performing pathological and biochemical tests, and Miss A. Russo for expert technical assistance.

\section{References}

Barry, M., Cartei, G., and Sherlock, S. (1969). Differential ferrioxamine test in haemochromatosis and liver diseases. Gut, 10, 697-704.

Bomford, A., Eddleston, A. L. W. F., Kennedy, L. A., Batchelor, J. R., and Williams, R. (1977). Histocompatability antigens as markers of abnormal iron metabolism in patients with idiopathic haemochromatosis and their relatives. Lancet, 1, 327-329.

Bothwell, T. H., and Finch, C. A. (1962) Iron Metabolism, Little Brown: Boston.

Cox, T. M., and Peters, T. J. (1978). Uptake of iron by duodenal biopsy specimens from patients with iron deficiency anaemia and primary haemochromatosis. Lancet, 1, 123-124.

Crosby, W. H. (1966). Heredity of hemochromatosis. In Controversy in Internal Medicine, pp. 261-270. Edited by F. J. Ingelfinger, A. S. Relman, and M. Finland, Saunders: Philadelphia.

Crosby, W. H. Likhite, V. V., O'Brien, J. E., and Forman, D. (1974). Serum iron levels in ostensibly normal people. Journal of the American Medical Association, 227, 310-312.

Edwards, C. Q., Carroll, M., Bray, P., and Cartwright, G. E. (1977). Hereditary hemochromatosis: diagnosis in siblings and children. New England Journal of Medicine, 297, 7-13.

Feller, E. R., Pont, A., Wands, J. R., Carter, E. A., Foster, G., Kourides, I. A., and Isselbacher, K. J. (1977). Familial hemochromatosis, physiological studies in the precirrhotic stage of the disease. New England Journal of Medicine, 296, 1422-1426.

Fillet, G., and Marsaglia, G. (1975). Idiopathic haemochromatosis: abnormality in RBC transport of iron by the reticuloendothelial system. Blood, 46, 1007.

Finch, S. C., and Finch, C. A. (1955). Idiopathic haemochromatosis, an iron storage disease. Medicine, 34, 381-430.

Grace, N. D., and Powell, L. W. (1974). Iron storage disorders of the liver. Gastroenterology, 67, 1257-1283.

Halliday, J. W., Gera, K. L., and Powell, L. W. (1975). Solid phase radio-immunoassay for serum ferritin. Clinica Chimica Acta, 58, 207-214.

Halliday, J. W., Russo, A. M., Cowlishaw, J. L., and Powell, L. W. (1977). Serum-ferritin in the diagnosis of haemochromatosis. A study of 43 families. Lancet, 2, 621-624.

Jacobs, A., Miller, F., Worwood, M., Beamish, M. R., and Wardrop, C. A. (1972). Ferritin in the serum of normal subjects and patients with iron deficiency and iron overload. British Medical Journal, 4, 206-208.

Lipschitz, D. A., Cook, J. D., and Finch, C. A. (1974). A clinical evaluation of serum ferritin as an index of iron stores. New England Journal of Medicine, 290, 1213-1216.

Peters, T., Giovanniello, T. J., Apt, L., and Ross, J. F. (1956). A new method for the determination of serum iron binding capacity. Journal of Laboratory and Clinical Medicine, 48, 274-279.

Powell, L. W. (1970). Changing concepts in haemochromatosis. Postgraduate Medical Journal, 46, 200-209. 
Powell, L. W. (1965). Iron storage in relatives of patients with haemochromatosis and in relatives of patients with alcoholic cirrhosis and haemosiderosis. Quarterly Journal of Medicine, 34, 427-442.

Powell, L. W. (1966). Normal human iron storage and its relation to ethanol consumption. Australasian Annals of Medicine, 15, 110-115.

Powell, L. W., Campbell, C. B., and Wilson, E. (1970). Intestinal mucosal uptake of iron and iron retention in idiopathic haemochromatosis as evidence for a mucosal abnormality. Gut, 11, 727-731.

Powell, L. W., and Kerr, J. F. R. (1975). The pathology of the liver in haemochromatosis. In Pathobiology Annual. Edited by H. Joachim. Appleton Century Crofts: New York.

Prieto, J., Barry, M., and Sherlock, S. (1975). Serum ferritin in patients with iron overload and with acute and chronic liver diseases. Gastroenterology, 68, 525-533.

Scheuer, P. J., Williams, R., and Muir, A. R. (1962). Hepatic pathology in relatives of patients with haemochromatosis. Journal of Pathology and Bacteriology, 84, 53-64.

Simon, M., Bourel, M., Fauchet, R., and Genetet, B. (1976).
Association of HLA-A3 and HLA-B14 antigens with idiopathic haemochromatosis. Gut, 17, 332-334.

Simon, M., Bourel, M., Genetet, B., Fauchet, R, Edan, G., and Brissot, P. (1977). Idiopathic hemochromatosis and iron overload in alcoholic liver disease. Differentiation by HLA phenotype. Gastroenterology, 73, 655-658. Walters, G. O., Miller, F. M., and Worwood, M. (1973). Serum ferritin concentration and iron stores in normal subjects. Journal of Clinical Pathology, 26, 770-772.

Wands, J. R., Rowe, J. A., Mezey, S. E., Waterbury, L. A., Wright, J. R., Halliday, J. W., Isselbacher, K. J., and Powell, L. W. (1976). Normal serum ferritin concentrations in precirrhotic hemochromatosis. New England Journal of Medicine, 294, 302-305.

Williams, R., Scheuer, P. J., and Sherlock, S. (1962). The inheritance of idiopathic haemochromatosis. A clinical and liver biopsy study of 16 families. Quarterly Journal of Medicine, 31, 249-265.

Williams, R., Smith, P. M., Spicer, E. J. F., Barry, M., and Sherlock, S. (1969). Venesection therapy in idiopathic haemochromatosis. Quarterly Journal of Medicine, 38, 1-16. 